\title{
Videoaulas e divulgação de conteúdos gramaticais para exames como o ENEM
}

\author{
João Vitor Bezerra Laurentino ${ }^{1}$ \\ Williany Miranda da Silva ${ }^{2}$
}

\section{Resumo}

As tecnologias digitais contribuem cada vez mais no contexto educacional, por esta razão, o presente texto versa acerca de materiais didáticos desta natureza. Assim, expóe o tratamento dado aos conteúdos gramaticais de língua portuguesa em videoaulas recomendadas para o ENEM. Adotamos a pesquisa qualiquantitativa, a partir da netnografia. Os dados constam em três sites (https://canaldoensino.com.br/blog/; http://ensinomédiodigital.fgv.br/ e http:// mesalva.com/) e destacam a sintaxe como o conteúdo gramatical mais recorrente. Constatamos um tratamento que une diferentes mídias no processo de didatização. Em alguns casos identificamos a predominância do processo multimodal, e, em outros, do hipermodal. Por fim, observamos que, apesar de apresentarem tratamentos que utilizam recursos diferentes, permanece nelas a exposição gramatical e a exemplificação desenvolvidas a partir de frases isoladas, sinalizando a inserção em um paradigma tradicional do ensino de língua.

Palavras-chave: videoaula; multimodalidade e hipermodalidade; conteúdos de sintaxe.

\section{Video lessons and dissemination of grammatical contents for exams such as ENEM}

\section{Abstract}

Digital technologies increasingly contribute to the educational context, for this reason, the present text is about teaching materials of this nature. Thereby, it exposes the treatment given to grammatical contents of Portuguese language in video lessons recommended for ENEM. We adopted qualitative and quantitative research, based on the netnography. The data are contained in three sites (https://canaldoensino.com.br/blog/; http://ensinomédiodigital.fgv. $\mathrm{br} / \mathrm{and}$ http://mesalva.com/) and evidences the syntax as the most recurrent grammatical content. We found a treatment that unites different media in the process of didatization. In some cases it was identified the predominance of the multimodal process, and in others, of the hypermodal. Finally, we observe that the video lessons have treatments that use different

1 Graduado em Letras, pela Universidade Federal de Campina Grande (UFCG), e professor de Língua Portuguesa da educação básica do estado da Paraíba. E-mail: joaovitorlaurentino@hotmail.com.

2 Professora Doutora da Unidade Acadêmica de Letras e membro do Programa de Pós-Graduação em Linguagem e Ensino (PPGLE) da Universidade Federal de Campina Grande (UFCG). E-mail: williany.miranda@gmail.com. 
resources, but the grammatical exposure and the exemplification developed from isolated sentences remain in them, signaling the insertion in a traditional language teaching paradigm. Keywords: video lessons; multimodality and hypermodality; contents of syntax.

\section{Introdução}

A popularização do mundo digital nas práticas cotidianas revela avanços concretos ante a diversidade de informação disponível aos usuários no universo da internet. No campo da educação também não é diferente, uma vez que canais abertos e sites, destinados à divulgaçáo de conteúdos das mais diversas áreas, estão disponíveis e crescem a cada dia. Para dar conta dessa variedade, despertando o interesse do público-alvo, os responsáveis pelos ambientes digitais recorrem a todo tipo de atrativo, desde a escolha lexical dos títulos e endereços até os tipos de letras, fontes, acrescidos de forte apelo visual. Tendo em vista a inserção tecnológica e o letramento digital, a Base Nacional Comum Curricular (BNCC) (BRASIL, 2018, p. 11), nas competências gerais, prevê a utilização de diferentes linguagens no ensino, dentre elas, a digital. O compartilhamento de informaçóes e a facilidade de acesso aos materiais disponíveis na rede tornaram-se uma grande oportunidade para professor e aluno utilizarem essa ferramenta como opção complementar de conhecimento. É nesse contexto que se situa um tipo particular de instrumento - as videoaulas. Foco central de nosso trabalho, elas possibilitam um estudo complementar e autônomo por parte do usuário interessado, permitindo uma aprendizagem nos moldes de uma Educação a Distância (EaD), de modo a complementar a formação de estudantes que se preparam para o Exame Nacional do Ensino Médio - ENEM.

Este artigo resulta das discussóes do projeto Uso de videoaulas na divulgação de conteúdos gramaticais em sites recomendados para o ENEM (PIBIC/ CNPq/UFCG - 2017-2018), vinculado a um projeto mais amplo, intitulado Configuraçôes de ensino em práticas multidisciplinares de linguagem (ns) (20182022), sob a coordenação dos professores doutores Edmilson Luiz Rafael e Williany Miranda da Silva, membros da linha de pesquisa Ensino de Língua e Formação Docente, do Programa de Pós Graduação em Linguagem e Ensino (PPGLE) da Universidade Federal de Campina Grande.

Em linhas gerais, o artigo procura responder qual é o tratamento dado aos conteúdos gramaticais de língua portuguesa em videoaulas recomendadas para o ENEM, pautando-se por objetivos específicos: 1) identifi- 
car os conteúdos gramaticais presentes em videoaulas, destinadas ao ensino complementar de prováveis candidatos que se submetem a esse tipo de exame; e 2) analisar o uso de estratégias de didatização na exposição de vários tópicos gramaticais. É imprescindível destacar que o corpus está disponível em três sites: https://canaldoensino.com.br/blog/ (Site 01); http://ensinomediodigital.fgv.br/ (Site 02) e http://mesalva.com/ (Site 03).

Definidos os objetivos e construído o corpus, definimos o eixo teórico, Ensino de Gramática em videoaulas, subdividindo-o em três subseçóes com vistas a cobrir nossas reflexôes sobre o tema. Além da fundamentação teórica, contemplamos mais duas seçóes, uma para descrever a abordagem teórico-metodológica para a sistematização das videoaulas em análise, e outra para a discussão dos resultados. Por fim, apresentamos as consideraçóes finais e as referências.

\section{Ensino de Gramática em videoaulas}

\section{Paradigmas de ensino e o eixo de análise linguística}

De acordo com Kuhn (1991, p. 95), a ciência é alicerçada em paradigmas que sustentam e fomentam suas teorias e atividades desenvolvidas. Não é diferente na educação, esta se apresenta também baseada em paradigmas, a partir dos quais se constroem currículos e práticas de ensino. $\mathrm{Na}$ contemporaneidade, é perceptível a coexistência conflituosa de dois paradigmas, o tradicional e o da complexidade.

No paradigma tradicional, para Flach e Behrens (2008, p. 10121), encontramos um aluno receptor e ouvinte. Ribeiro et al. (2010) defendem que a pedagogia tradicional é behaviorista, o aluno acumula conhecimentos transmitidos pelo professor através da "memorização mecânica, por intermédio de um ensino descontextualizado e pouco interativo" (RIBEIRO; LOBATO; LIBERATO, 2010, p. 34). Conforme Flach e Behrens (2008, p. 10125), no paradigma emergente, encontramos um aluno como um ser complexo e competente, visando a construção do conhecimento e a formação crítica. Na sala de aula, o aluno é o sujeito da prática educativa. Este paradigma, frente à contemporaneidade, parece-nos responder às necessidades educativas da sociedade brasileira em processo de digitalização.

Ambos os paradigmas interferem na formação e na prática docente, recorrentes em aulas presenciais como as de língua portuguesa. Em especial, 
porque defrontamo-nos com diversos questionamentos subjacentes ao ensino de língua na educação básica. Abrem-se vieses para a ação docente no que se refere a este estudo, dentre eles a perspectiva da gramática normativa tradicional e a da análise linguística. Em geral, a primeira está ligada à atividade tradicional do ensino, pautado na metalinguagem e nos conteúdos de base prescritiva, a partir de um método transmissivo. Por outro lado, a prática da análise linguística, de alicerce reflexivo e produtivo, encontra, numa aula de um paradigma emergente, ambiente propício.

A análise linguística foi preconizada há duas décadas nos Parâmetros Curriculares Nacionais (BRASIL, 1998) e, atualmente, pela Base Nacional Comum Curricular (BRASIL, 2018) em sua versão final. Segundo Bezerra e Reinaldo (2013), este eixo corresponde a um conjunto de atividades linguísticas e epilinguísticas, orientadas por uma perspectiva teórica, primando pela palavra e seu funcionamento textual-discursivo em textos de gêneros variados. Se orientada pelo aspecto gramatical da tradição, "a terminologia da gramática tradicional é retomada, como conhecimento tácito” (BEZERRA; REINALDO, 2013, p. 61).

De acordo com Reinaldo (2012, p. 240), a análise linguística é um procedimento que conduz o aluno a (re)conhecer tanto o sistema como as normas linguísticas por meio de uma classificação e de uma nomenclatura, mas, ao mesmo tempo, de questioná-las caso não sejam suficientes para descrever os fatos da língua. Assim, pode desenvolver-se no paradigma da complexidade, o qual, na perspectiva holística, visa a formação crítica e reflexiva do aluno, conforme indicam Flach e Beherens (2008).

Em muitas escolas, o ensino de português na educação básica insiste ainda numa gramática com características prescritivas, mesmo com as exigências do mundo contemporâneo e com outros procedimentos disponíveis, como a análise linguística. Desse modo, contribui para a hegemonização da variedade padrão, em detrimento das outras variedades da língua, deixando-se à margem aspectos produtivos. Nas aulas de português, os tipos de ensino fornecem tratamentos diferentes aos conteúdos gramaticais - os aspectos produtivo, descritivo e prescritivo refletem-se na prática docente em sala, mas também nos diversos materiais didáticos, sejam eles digitais ou não.

\section{A sintaxe do período composto e o ensino}

O conteúdo de sintaxe assume um lugar central, face à saliência dos dados em análise, conforme os quadros - Quadro 01, "Recorrência de cate- 
gorias gramaticais em videoaulas", e o Quadro 02, "Conteúdos de sintaxe" explicitam na seção Procedimentos metodológicos. Assim, voltamo-nos ao conteúdo sintático da língua portuguesa e, em especial, à relação estabelecida entre as oraçóes no período composto. Os conteúdos sobre coordenação, subordinação e correlação orientam uma revisitação sobre tais conceitos e sobre o estudo das relaçóes sentenciais do período como forma de compreender o tratamento que lhes são conferidos no ambiente digital.

De acordo com Garcia (1986) e Cunha e Cintra (2007), o período composto é normalmente estruturado pelas oraçóes que o constituem e se interligam a partir de dois processos sintáticos universais, a coordenação e a subordinação. Para Cunha e Cintra (2007), na coordenação, as orações são autônomas, independentes, cada uma com um sentido próprio. Nesta ótica, a coordenação é um fator semântico; entretanto, Cunha e Cintra (2007) também apontam que as oraçóes coordenadas não atuam como complemento do verbo da oração principal, pelo viés sintático. Para esses autores, a coordenação pode ser: a) assindética, desprovida de conectivo, apresenta-se, assim, justaposta; e b) sindética, uma vez que está ligada por uma conjunção conectiva.

Castilho (2010) demonstra, com base na linguística moderna, a coordenação como um procedimento de combinação sintática, por vezes, com conectivo ou por justaposição. Ademais, ainda elenca os critérios diferenciadores entre a coordenação e a subordinação. Por exemplo, as sentenças são equivalentes na coordenação e não funcionam como constituintes de outras sentenças (como é o caso das subordinadas), também os elementos coordenados possuem simetria semântica, o que não ocorre na subordinação.

A subordinação, para Cunha e Cintra (2007), corresponde à relação entre "oraçóes sem autonomia gramatical; isto é, oraçóes que funcionam como termos essenciais, integrantes ou acessórios de outra oração" (CUNHA; CINTRA, 2007, p. 608). Para eles, há três tipos de subordinação: orações subordinadas substantivas; b) oraçóes subordinadas adjetivas e c) oraçôes subordinadas adverbiais. Dentre elas, há outras divisões. As substantivas classificam-se como: subjetiva; objetiva direta; objetiva indireta; completiva nominal; predicativa; apositiva, quando exercem a função de aposto e por exercer a função de agente da passiva. As adjetivas podem ser restritivas ou explicativas. Por sua vez, as adverbiais podem ser causais; concessivas; condicionais; consecutivas; finais e temporais.

$\mathrm{Na}$ subordinação não ocorre o paralelismo de funções e valores sintáticos, havendo um processo de hierarquização entre as sentenças; Garcia 
(1986, p. 19) complementa: "qualquer oração subordinada é, na realidade, um fragmento de frase". No tocante à funcionalidade, Azeredo (2008, p. 298) explicita que uma oração subordinada ocupa a posição de substantivo, adjetivo, advérbio em outra oração, a qual é conhecida por principal ou superordenada. Entre a coordenação e a subordinação, distingue-se outro processo entre sentenças, no qual os enunciados mostram-se interdependentes, isto é, dependem um do outro mutuamente. De acordo com Rodrigues (2016, p. 225), a correlação corresponde ao "mecanismo de estruturaçáo sintática ou o procedimento sintático em que uma sentença estabelece relação de interdependência com outra no nível estrutural". A Gramática Tradicional (GT), em sua concepção binária para a compreensão do relacionamento entre sentenças, coordenação/subordinação, enquadra dentro delas as oraçóes correlatas - que são interdependentes entre si e que fogem às regras gerais.

Muitos aspectos da tradição gramatical, referentes ao estudo da sintaxe, destoam do que seria uma abordagem da língua de base descritiva e científica. Dentre eles, situa-se a mistura de critérios semânticos e sintáticos, sinalizada por Perini (1985). Sperança-Criscuolo (2016, p. 73) revela que gramáticas, livros didáticos e muitos outros materiais que servem de apoio ao ensino de Língua Portuguesa trazem uma abordagem que privilegia os aspectos mais formais e classificatórios. A utilização de frases isoladas apenas para fins de classificação também se constitui como um exercício de cunho tradicional, que náo direciona o aluno ao emprego consciente da sintaxe para atingir propósitos comunicativos.

Espera-se que aulas de sintaxe, que estejam inseridas no paradigma da complexidade, valham-se, ao menos, de reflexóes críticas e de dados reais da língua - o texto; afinal, o conhecimento de sintaxe fornece ao falante o maior controle dos mecanismos sintáticos e maior versatilidade e autonomia ao utilizá-los, conforme Sperança-Criscuolo (2016, p. 77). Como também, é possível a partir dos conceitos da tradição - exigidos pela escola e pela sociedade - percorrer o caminho da análise linguística, como estratégia metodológica.

\section{Videoaulas: textos multimodais $\mathbf{x}$ hipermodais}

As videoaulas inserem-se como recursos tecnológicos, as quais, enquanto ferramentas digitais, são suscitadas pela BNCC (BRASIL, 2018). 
Em essência, desenvolvem-se a partir de objetivos educacionais. Barreré (2014) apresenta que estão disponíveis na rede um número significativo de videoaulas. Assim, são diversos os conteúdos abordados, entre os quais estão os de gramática. Dentre as características deste gênero, situam-se a multimodalidade e a hipermodalidade.

Conforme Dionísio (2006), a multimodalidade corresponde a um traço constitutivo do discurso oral ao escrito, como também diz respeito aos arranjos não padrão que a escrita vem apresentando na mídia em função do desenvolvimento tecnológico. Dionísio (2006, p. 136) defende ainda que todo gênero textual é multimodal, mas que há diferentes níveis de manifestação desta característica, a qual pode ser disposta em um contínuo que vai do menos ao mais visualmente informativo. Nesta perspectiva, as videoaulas podem ser concebidas como multimodais mais visualmente informativas, por utilizarem mais de um modo de representação como forma de expressão. Tais recursos, como desenhos, fotos, gráficos e tabelas, por exemplo, são elementos que exercem funçóes retóricas na construção dos sentidos. Assim, imagens e ícones utilizados, como também a própria disposição gráfica na tela, são semioticamente significativos.

Dentro de uma estrutura hipertextual ou de hipermídia, a união entre texto verbal, imagens, imagens em movimento e som, isto é, diferentes mídias, constrói uma relação de hipermodalidade. Para Braga (2004, p.146), a utilização de mídias de natureza diversa funda uma nova realidade comunicativa, ultrapassa as possibilidades interpretativas mais tradicionais da multimodalidade. Neste prisma, estas representaçóes complementam-se, coordenam-se e integram-se no gênero. Assim, há videoaulas com estas características.

Barreré (2014, p. 77), do ponto de vista computacional, define a videoaula como constituída por elemento de ação multimídia, sincronizada espacial e temporal com outras mídias (áudio, texto ou imagem). Barreré et al. (2011, p. 4) apresentam-na como uma "aplicação multimídia que permite a apresentação de vídeo, slides e outros documentos de forma sincronizada e com possibilidade de navegação em um roteiro". Outra característica é o aspecto sistemático das informações, pois podem apresentar áudio ou imagens em movimento, ou ambos em concomitância, por exemplo. O elevado número de videoaulas disponíveis é o que torna necessária a determinação de critérios de seleção, tornando-se produtiva uma investigação que 
verifique a abordagem pedagógica e a profundidade aplicada ao conteúdo desse instrumento.

\section{Procedimentos metodológicos}

Esta pesquisa apresenta uma abordagem quantiqualitativa, porque quantifica e descreve videoaulas de gramática disponíveis na rede. Situa-se como documental, uma vez que os vídeos são documentos, na perspectiva de Le Goff (1997). Possui natureza netnográfica, na perspectiva de Rocha e Montardo (2005). Para recolher os dados de fala presentes nas videoaulas com recurso auditivo, adotamos a transcriçáo, a partir dos critérios fornecidos por Dionísio (2009). E para a reprodução das imagens (recurso visual) utilizamos capturas de tela. Os sites, de onde as videoaulas são provenientes, foram selecionados com base na indicação realizada pelo Portal Canal do Ensino (disponível no link: https://canaldoensino.com.br/blog/12-sites-para-estudar-de-graca-para-o-enem), com disponibilidade de videoaulas gratuitas. Para o nosso corpus, as videoaulas foram colhidas entre fevereiro e junho de 2018, estando presentes nos sites Canal do Ensino (site 01: https:// canaldoensino.com.br/blog/); Ensino Médio Digital (site 02: http://ensinomediodigital.fgv.br/) e Me Salva (site 03: http://mesalva.com/); definidos a partir do critério de gratuidade do acesso aos vídeos e da existência de materiais voltados à gramática, previamente selecionados em pesquisa anterior.

Os três sites supracitados apresentam características semelhantes, dentre elas, o caráter pedagógico e complementar de conhecimentos gramaticais direcionados aos usuários desejosos em complementar seus estudos sobre a língua portuguesa e que acreditam encontrar, nestes ambientes, subsídios que supram as lacunas de conhecimento específico. O corpus - as videoaulas - está alocado nesses sites e organiza-se com base em vídeos que têm, dentre os conteúdos elencados, o aspecto gramatical como central, conforme o objetivo da investigação. O Quadro 01, a seguir, destaca o índice desses conteúdos, vejamos: 
Quadro 01- Recorrência de categorias gramaticais em videoaulas

\begin{tabular}{|c|c|c|c|c|}
\hline \multirow{2}{*}{$\begin{array}{c}\text { Categorias } \\
\text { gramaticais }\end{array}$} & $\mathbf{0 1}$ & $\mathbf{0 2}$ & $\mathbf{0 3}$ & $\begin{array}{c}\text { Exibiçáo de videoaulas } \\
\text { videoaulas por } \\
\text { categoria }\end{array}$ \\
\cline { 2 - 5 } & $73(36,5 \%)$ & $5(14,8 \%)$ & $4(12,12 \%)$ & $82(30,7 \%)$ \\
\hline $\begin{array}{c}\text { Fonética e } \\
\text { Fonologia }\end{array}$ & $95(47,5 \%)$ & $9(26,4 \%)$ & $8(24,24 \%)$ & $112(42 \%)$ \\
$\begin{array}{c}\text { Morfologia } \\
\text { Semântica, } \\
\text { Pragmática e } \\
\text { Estilística } \\
\text { Sintaxe }\end{array}$ & $4(2 \%)$ & $1(3 \%)$ & $0(0 \%)$ & $5(1,9 \%)$ \\
Outros & $26(13 \%)$ & $12(35,3 \%)$ & $8(24,24 \%)$ & $46(17,2 \%)$ \\
\hline $\begin{array}{c}\text { Total de videoaulas } \\
\text { por site: }\end{array}$ & $200(100 \%)$ & $34(100 \%)$ & $33(100 \%)$ & $267(100 \%)$ \\
\hline
\end{tabular}

O Quadro 01, "Recorrência de categorias gramaticais em videoaulas", permite a visualização quantitativa da reincidência das categorias gramaticais nos três sites mencionados, identificados na primeira coluna à esquerda como: 1) Fonética e fonologia; 2) Morfologia; 3) Semântica, pragmática e estilística; 4) Sintaxe e 5) Outros (denominação indefinida pelos moldes clássicos: variação linguística, concepção de linguagem, por exemplo). A contabilidade, para cada categoria, evidencia um índice maior para conteúdos decorrentes do agrupamento Fonética e Fonologia, (30.7\%); Morfologia (42\%) e Sintaxe (17,2\%), enquanto o agrupamento das categorias Semântica, Pragmática e Estilística $(1,9 \%)$ e Outros $(8,2 \%)$ reúne uma incidência de conteúdos bem menores, numericamente.

Apesar de incidências variadas e até quantitativamente mais representativa em outras categorias, optou-se por uma análise do conteúdo de sintaxe, em virtude de sua incidência mais equânime nos três sites. Dos conteúdos gramaticais, é este quem oferece contribuiçóes mais diretas à produção de texto, uma vez que as relaçóes que se estabelecem entre oraçôes e períodos, são cruciais à coesão, favorecendo a coerência textual. À sintaxe articulam-se as noçóes de concordância e regência verbal e nominal. Para textos inseridos em situações mais formais de comunicação, o emprego da concordância e regência, a partir dos critérios da tradição, é imprescindível; nesta perspectiva se insere a produção textual exigida pelo ENEM, textos do 
gênero dissertativo argumentativo. Após a definição da categoria, organizaram-se os conteúdos mais frequentes, conforme se verifica no Quadro 02, a seguir. Vejamos:

Quadro 02 - Conteúdos de sintaxe

\begin{tabular}{|c|c|c|c|c|}
\hline \multicolumn{4}{|c|}{ Exibiçáo de videoaulas } \\
\hline $\begin{array}{c}\text { Conteúdos de } \\
\text { sintaxe }\end{array}$ & \multicolumn{3}{|c|}{ SITES } & $\begin{array}{c}\text { Total de } \\
\text { videoaulas por } \\
\text { conteúdo de } \\
\text { sintaxe }\end{array}$ \\
\cline { 2 - 5 } & $\mathbf{0 1}$ & $\mathbf{0 2}$ & $\mathbf{0 3}$ & $19(41,3 \%)$ \\
Período simples & $12(46 \%)$ & $3(25 \%)$ & $4(50 \%)$ & $13(28,3 \%)$ \\
Período composto & $6(23 \%)$ & $3(25 \%)$ & $4(50 \%)$ & $14(30,4 \%)$ \\
\hline $\begin{array}{c}\text { Total de videoaulas por } \\
\text { site: }\end{array}$ & $26(100 \%)$ & $12(100 \%)$ & $8(100 \%)$ & $46(100 \%)$ \\
\hline
\end{tabular}

O Quadro 02, "Conteúdos de sintaxe", sinaliza a predominância de "Período composto" como o conteúdo de abordagem mais sistemática, apesar de náo ser o tópico mais recorrente nos sites 01 e 02 . Ante tal incidência, estudamos e refletimos sobre as videoaulas com este conteúdo. A partir de características constitutivas, foi possível dividi-las em dois grupos. Estão presentes no primeiro grupo, videoaulas com predominância de recursos visuais, disponíveis nos sites 01 e 02 . Já para o segundo grupo, reunimos as disponíveis no site 03, que apresentavam uma predominância de recursos visuais e sonoros. Com tal reconhecimento, estabeleceram-se dois encaminhamentos, definidos como categorias de análise: 1 . Tratamento que considera a multimodalidade; e 2 . Tratamento que considera a hipermodalidade.

A reflexão que empreendemos diz respeito à ilustração de duas figuras, como representativos de cada categoria definida. Vejamos na sequência.

\section{Análise dos dados}

Conforme exposto, as diferentes representaçóes de linguagem na constituição de videoaulas formam-se pela integração de mais de uma mídia, no ensejo de atingir seus propósitos educacionais. Essa característica conduz-nos a uma análise em que se distinguem dois conceitos teóricos cen- 
trais, a multimodalidade e a hipermodalidade, como formas de abordar os conteúdos gramaticais em foco: o período composto. O Quadro 03 sintetiza as discussões que seguem:

Quadro 03 - Tratamentos e recursos empregados nas videoaulas de sintaxe do período composto

\begin{tabular}{|c|c|c|c|c|}
\hline \multicolumn{5}{|c|}{ Videoaulas de sintaxe do período composto } \\
\hline $\begin{array}{c}\text { Grupos de } \\
\text { videoaulas }\end{array}$ & $\begin{array}{c}\text { Tratamento que } \\
\text { considera a }\end{array}$ & Recursos & Sites & $\begin{array}{c}\text { Total de } \\
\text { videoaulas } \\
\text { por recursos } \\
\text { empregados }\end{array}$ \\
\hline 01 & Multimodalidade & Sem animação & 02 & $6(46,2 \%)$ \\
\cline { 3 - 5 } & Hipermodalidade & $\begin{array}{c}\text { Animação e } \\
\text { recurso auditivo }\end{array}$ & 03 & $3(23 \%)$ \\
\hline 02 & Total final de videoaulas de sintaxe do período composto & $13(100 \%)$ \\
\hline
\end{tabular}

\section{Tratamento que considera a multimodalidade}

O Quadro 03, “Tratamentos e recursos empregados nas videoaulas de sintaxe do período composto", evidencia que, num total de treze (100\%), nove $(79,2 \%)$ podem ser reconhecidas como multimodais. Estas videoaulas são constituídas, predominantemente, de recursos visuais, em que figuram imagens, imagens em movimento associadas à disposição gráfica, à escolha de fontes e cores, que constituem os elementos visuais e os arranjos que compóem seus leiautes. Além dos recursos mencionados, a animação prevalece em três deles, correspondendo a $23 \%$ do total; nas demais videoaulas desta categoria de análise, as seis restantes, equivalente a 46,2\%, não se constatam animação. Para ilustrar as categorias elencadas,

A Figura 01, a seguir, reproduz uma caricatura, com traços como o bigode farto, cavanhaque e os óculos, uma marca inconfundível de um clássico autor da literatura brasileira, Machado de Assis. A proposta de exibição parece promover um grau de interatividade maior com o internauta, porque depende de uma açáo de avançar ou retroceder, a partir de um comando, a fim de que a videoaula atinja seu objetivo. Esta videoaula de gramática faz parte de uma sequência, precedida por conteúdos de literatura e sucedida 
pela produção de texto. Entretanto, não há integração entre estes eixos e o conteúdo gramatical, consequência do reflexo do método cartesiano, que preza pela decomposiçáo do conhecimento, com base em Flach e Behrens (2008). A videoaula, em destaque, aborda o conteúdo "tipos de subordinação". Vejamos a Figura 01 e o fragmento seguinte:

Fig. 01 - Representação de imagem de videoaula multimodal com animação, divulgada pelo site Ensino Médio Digital

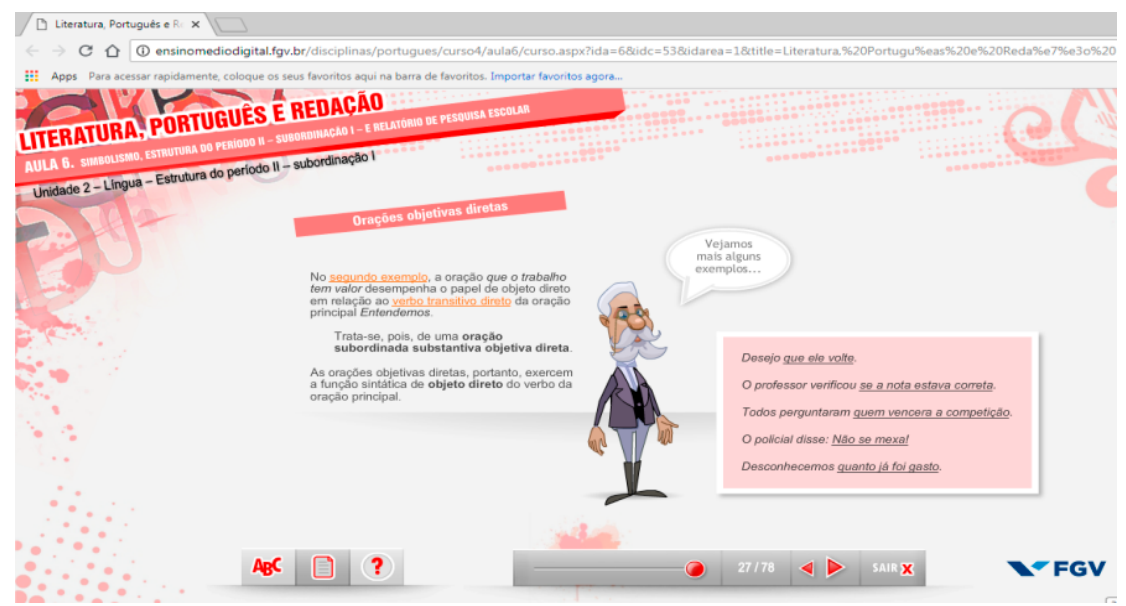

Disponível em: http://ensinomediodigital.fgv.br/cursos/literatura-portugues-redacao. Acesso em: 16 jun. 2018.

Fragmento 01: Transcrição do conteúdo de videoaula divulgada pelo site 02

/.../desempenha o papel de objeto direto em relação ao verbo transitivo direto da oração /.../ Trata-se, pois, de uma oração subordinada substantiva objetiva direta. As oraçóes objetivas diretas, portanto, exercem a função de objeto direto do verbo da oração principal /.../ Exemplos... Desejo que ele volte. O professor verificou se a nota estava correta. Todos perguntaram que vencera a competição. O policial disse: não se mexa! /... " Podemos encontrar, ainda, orações com funções de agente da passiva, que, contudo, não são reconhecidas pela Nomenclatura Gramatical Brasileira - NGB. A prova foi vencida por quem merecia" /.../ Clique aqui e leia atentamente ao texto Um apólogo. A seguir, responda as questóes propostas... /.../ Sublinhe as orações subordinadas substantivas presentes oraçóes apresentadas a seguir e preencha as lacunas com a classificação /.../ ...para fingir que vale alguma cousa neste mundo? Disponível em: http://ensinomediodigital.fgv.br/cursos/literatura-portugues-redacao. Acesso em: 16 jun. 2018. 
O fragmento 01 diz respeito à transcrição das quatro etapas da videoaula em que aparecem as informaçóes sobre o conteúdo: explicação dos conceitos, análise de exemplos, apresentação de "observaçóes" e a aplicação de exercício de verificação de aprendizagem. Como exemplo do primeiro movimento, temos que após a exposição da nomenclatura e da tipologia da subordinação de forma mais geral, evidencia-se o conceito de oração subordinada objetiva direta: "Trata-se, pois, de uma oração subordinada substantiva objetiva direta. As oraçôes objetivas diretas, portanto, exercem a função de objeto direto do verbo da oraçáo principal" (linhas 2-3). Este trecho da primeira etapa fornece subsídios para que o internauta aluno possa realizar a análise de exemplos. Também são perceptíveis a ênfase e a repetição, concedidas ao termo "objeto direto", fazendo uso do método da memorização, o que sinaliza um tratamento tradicional, mecânico e behaviorista, conforme Ribeiro et al. (2010). O excerto, a seguir, ilustra o segundo movimento, de exemplificação: "Exemplos... Desejo que ele volte. O professor verificou se a nota estava correta. Todos perguntaram quem vencera a competição. O policial disse: não se mexa!" (linhas 3-5), por meio deste, com vistas à apreensão das classificaçóes. Para tanto, a videoaula parte de frases isoladas, revelando uma ação pedagógica voltada à taxonomia sintática, em detrimento de uma gramática do uso, do gênero textual (SPERANÇA-CRISCUOLO, 2016).

A terceira etapa da aula explicita outras características do conteúdo, como a apresentação de observaçóes em: "Podemos encontrar, ainda, oraçóes com funçóes de agente da passiva, que, contudo, não são reconhecidas pela Nomenclatura Gramatical Brasileira - NGB. A prova foi vencida por quem merecia" (linhas 5-7). Esta informação é nova, porque emerge das variaçóes não padrão, contrariando a exclusividade da NGB; embora não apresentem reflexóes mais consistentes que as envolvam.

A etapa final corresponde à aplicação de um exercício, a partir do conto: "Um apólogo", escrito por Machado de Assis. A partir dele, é fornecido um comando para resolver uma atividade: "Sublinhe as oraçóes subordinadas substantivas presentes nas oraçóes apresentadas a seguir e preencha as lacunas com a classificação" (linhas 8-10). Para a adequada solução, as frases a serem classificadas foram retiradas do texto machadiano. Tanto o comando fornecido no enunciado da questáo como a natureza e o emprego das frases demonstram uma abordagem da gramática, inserida em um paradigma tradicional; portanto, mais distante de uma metodologia pautada na análise linguística. O texto literário é usado em favor da gramática para a realização 
da análise sintática, resultando em uma prática antiga num novo suporte (tecnológico).

\section{Tratamento que considera a hipermodalidade}

De acordo com Braga (2004), a hipermodalidade ultrapassa as possibilidades interpretativas dos textos mais tradicionais. Ao unir diferentes mídias através de hiperlinks, funda-se uma nova realidade comunicativa. E o vídeo é um dos suportes que possibilita a geração desta realidade, nele se une a imagem em movimento à escolha de fontes, de cores, aos desenhos, mas desta vez, com uma mídia diferenciadora: o áudio. O áudio é o elemento que distingue as videoaulas multimodais (com e sem animação) das hipermodais. O Quadro 03 "Tratamentos e recursos empregados nas videoaulas de sintaxe do periodo composto" coloca esse produto no segundo grupo, com uma amostra de quatro delas, o que corresponde à 30,8\%. A Figura 02 e o Fragmento 02 correspondem a uma amostragem representativa desta categoria. Vejamos:

Fig. 02 - Reprodução de imagem de videoaula hipermodal divulgada pelo site Me Salva

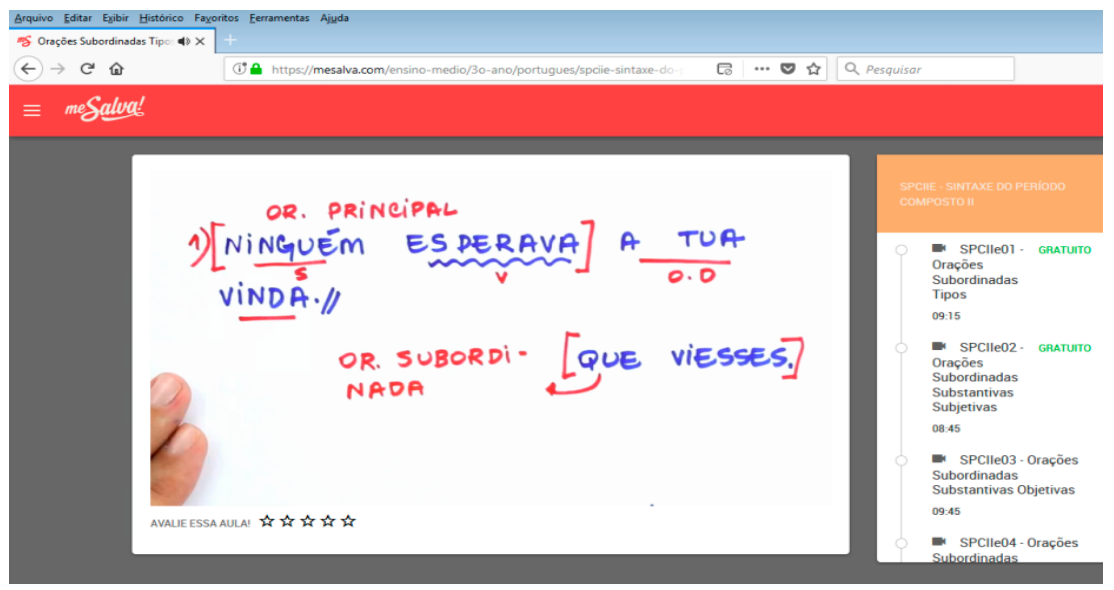

Disponível em: https://www.mesalva.com/ensino-medio/3o-ano/portugues/spciie-sintaxedo-periodo-composto-ii/spciie01-oracoes-subordinadas-tipos. Acesso em: 26 fev. 2018. 
Fragmento 02: Transcrição de áudio sobre sintaxe divulgado em videoaula no site "Me salva"

/.../ conhecer a classificação das oraçóes subordinadas de maneira bem simples nós temos as subordinadas as substantivas as adjetivas e as adverbiais observem que esses nomes eles nos são conhecidos e eles também não são dados à toa /.../ a classificação delas são essas três né é /.../ as oraçóes subordinadas substantivas se equivalem aos substantivos... as oraçóes subordinadas adjetivas se equivalem aos adjetivos... as oraçóes subordinadas adverbiais se equivalem a advérbios... /.../ vamos lembrar entáo desse processo chamado de... processo de composição do período que é a subordinação tudo bem? então primeira coisa que precisamos lembrar é que dentro da análise precisamos verificar se existe um período composto "ninguém esperava tua vinda" nesse caso nós temos apenas um verbo apenas esperar e a análise poderia só poderia ser a interna /.../ por exemplo se eu tivesse dito "ninguém espera que viesses" que viesses se no lugar desse objeto direto... que antes era era constituído por termos eu colocasse uma oração aí sim nós poderíamos fazer uma análise que está relacionada à coordenação e à subordinaçấo /.../ essa oraçâo principal tem como complemento uma outra oração

Disponível em: https://www.mesalva.com/ensino-medio/3o-ano/portugues/spciie-sintaxedo-periodo-composto-ii/spciie01-oracoes-subordinadas-tipos. Acesso em: 26 fev. 2018.

O Fragmento 02 exibe trechos editados de uma audiogravação correspondente, originalmente, a quatro minutos, em que um sujeito, no papel de professora, expóe o conteúdo com o apoio de imagens como a reproduzida na Figura 02. Na primeira etapa, a professora menciona que "nós temos as subordinadas as substantivas as adjetivas e as adverbiais observem que esses nomes eles nos são conhecidos" (linhas 1-3), destacando a relevância em nomear os tipos de subordinação, deixando em evidência conhecimentos sobre a sintaxe moldados na tradição gramatical.

Na segunda etapa em destaque, ou seja, nos trechos em itálico, percebe-se que a professora parte de uma pressuposição de que o conteúdo já é conhecido, como se constata em "primeira coisa que precisamos lembrar é que dentro da análise precisamos verificar se existe um periodo composto" (linhas 7 e 8). Essa relação parece justificar a introdução e consequente apreensão do novo conteúdo, razão pela qual ela o menciona e com o intuito de facilitar a exposição do novo conteúdo que ora se ocupa. Na terceira e última etapa destacada, podemos constatar o movimento de retomada à primeira, acrescentando-se exemplos, conforme se verifica em "por exemplo se eu tivesse dito "ninguém espera que viesses" (linha 10), como forma de consolidar a exposição do conteúdo. Além disso, simultaneamente à fala, a voz remete ao enunciado da lousa que apresenta as duas possibilidades: período simples e composto. 
Ao dividir a forma de exposição da videoaula a partir de três movimentos distintos e inter-relacionados, constatamos que, primeiramente, o sujeito - no papel de professor, enfatiza a nomenclatura ou classificaçáo dos períodos (identificação/classificação do fenômeno linguístico), depois, recorre a conhecimentos anteriores para consolidar o que está apresentando (retomada de informaçóes/memorização) e, por fim, exemplifica situações de transformação de períodos (exemplificação/transformação). Tais movimentos sinalizam o caráter reprodutor do ensino de língua materna, em seu estágio mais tradicional, com ênfase na metalinguagem. Reforça-se a opção pelo formal, com tendência prescritivista associada ao paradigma tradicional de ensino de língua, que desconsidera o uso reflexivo de situaçóes de linguagem, tanto nas videoaulas multimodais como nas hipermodais. Há diferentes formas de expor os conteúdos gramaticais, partindo da interação, integrando mídias visuais e sonoras, animaçôes, linguagem clara. Todas elas, porém, valem-se da tradição como subsídio teórico-metodológico. Este tratamento concedido à gramática nas videoaulas corrobora para a manutenção desta concepção prescritiva - realizada com ênfase na descrição e hegemonização da variedade padrão - que revela um discurso próprio da tradição. A prática educativa, que foi desenvolvida a partir deste conteúdo, preza por uma metodologia de ensino pautada na reprodução, no caráter acrítico e não reflexivo, semelhante ao que se defende numa prática tecnicista. Enquanto recursos tecnológicos, as videoaulas, por si, não podem conceder um tratamento de base inovador ao conteúdo de sintaxe do período composto, se os produtores enfatizam estas concepçóes de ensino e de língua. Observa-se, portanto, que apesar do uso de recursos atrativos diferentes para tratar conteúdos clássicos, prevalece nelas - videoaulas - a exposição gramatical e a exemplificação desenvolvidas a partir de frases isoladas. Constroem-se abordagens que náo privilegiam o texto, o gênero, o discurso, nem uma sintaxe que esteja a favor deles, nem o que se espera de um ensino com foco no paradigma da complexidade, mais condizente com uma abordagem de ensino e aprendizagem da contemporaneidade.

\section{Consideraçóes finais}

A identificação dos diversos conteúdos gramaticais, e, em específico, dos conteúdos de sintaxe permitiu verificar a abordagem teórico-metodológica para o seu tratamento. De início, com relação ao suporte, percebeu-se 
que as videoaulas multimodais promovem uma relação maior de interatividade com o internauta. $\mathrm{O}$ uso de tais recursos é o responsável por avançar e retroceder durante o decorrer de toda a videoaula. De mais a mais, disponibilizam-se exercícios que podem ser respondidos e corrigidos on-line, os quais fomentam a interação. Por outro lado, as videoaulas hipermodais acrescentam o recurso auditivo como diferenciador, que as distingue e as coloca nesta categoria. Nelas, a integração de mídias é ainda mais complexa, por mobilizar mais habilidades sensoriais do aluno, como também, mais recursos tecnológicos para sua produção e uso. Ambas as representantes das modalidades apresentam diferentes e dinâmicas formas de tratar o conteúdo, em busca de alcançar um número maior de internautas-alunos.

Em continuidade, a análise das transcriçóes evidencia estratégias de didatização, com foco no paradigma tradicional. Embora o ENEM exija de seus candidatos competências pautadas na interdisciplinaridade, na reflexão e na contextualização, as videoaulas de sintaxe do período composto, ilustradas pelas Figuras 01 e 02 e representativas dos sites 1, 2 e 3, que se propóem a subsidiar a formação do internauta-aluno, caminham por um viés oposto, reproduzindo um conhecimento fragmentado, descritivo e separado de seus contextos.

Por fim, mesmo inseridas em práticas mais tradicionais do ensino de português, este suporte, apesar de constituir-se também como um gênero direcionado a um público genérico não pode ser desprezado, seus usos devem estar associados a informaçóes adicionais, complementares ou orientados/reforçados pela figura docente. A integração de mídias revela um avanço tecnológico que nos conduz a acreditar que o material divulgado pelos sites também estaria à frente no que diz respeito ao ensino de gramática, embora os sites não se proponham a isto. Estudar esse tipo de material é uma forma de contribuir para melhorar a qualidade do que se tem acesso e do que se divulga como adequado e complementar ao ensino de língua.

\section{Referências}

AZEREDO, J. C. de. Gramática Houaiss da Lingua Portuguesa. São Paulo: Publifolha, 2008.

BARRERÉ, E. Videoaulas: aspectos técnicos, pedagógicos, aplicaçóes e bricolagem. Disponível em: http://www.br-ie.org/pub/index.php/pie/ article/view/3154/2668. Acesso em: 01 mar. 2018. 
.; SCORTEGAGNA, L.; LÉLIS, C. A. S. Produção de Videoaulas para o Serviço EDAD da RNP (Serviço Videoaula@RNP). Disponível em: http:// www.ufjf.br/eduardo_barrere/files/2011/11/ArtigoVideoaulaSBIE2011. pdf. Acesso em: 01 mar. 2018.

BEZERRA, M. A.; REINALDO, M. A. M. Análise linguistica: afinal a que se refere? São Paulo: Cortez, 2013.

BRAGA, D. B. A comunicação interativa em ambiente hipermídia: as vantagens da hipermodalidade para o aprendizado no meio digital. In: MARCUSCHI, L. A.; XAVIER, A. C. (org.). Hipertexto e gêneros digitais: novas formas de construção do sentido. Rio de Janeiro: Lucerna, 2010. p. 175-198.

BRASIL. Base Nacional Comum Curricular. Educação é a Base. Brasília, MEC/CONSED/UNDIME, 2017. Disponível em: http://portal.mec. gov.br/index.php?option=com_docman \&view=download $\&$ alias=79601 anexo-texto-bncc-reexportado-pdf-2\&category_slug=dezembro-2017pdf\&Itemid=30192. Acesso em: 14. abr. 2018.

- Ministério da Educação. Secretaria de Educação Fundamental. Parâmetros Curriculares Nacionais: terceiro e quarto ciclos do ensino fundamental: língua portuguesa. Brasília, DF: MEC/SEF, 1998.

CASTILHO, A. T. Nova gramática do português brasileiro. São Paulo: Contexto, 2010.

CUNHA, C.; CINTRA, L. F. L. Nova gramática do português contemporâneo. Rio de Janeiro: Lexikon, 2007.

DIONÍSIO, A. P. Análise da conversação. In: MUSSALIM, F.; BENTES, A. C. (org.). Introdução à Linguística. São Paulo: Cortez, 2009.

. Gêneros multimodais e multiletramentos. In: KARWOSKI, A. M.; GAYDECZKA, B.; BRITO, K. S. Gêneros textuais: reflexôes e ensino. Rio de Janeiro: Lucerna, 2006.

FLACH, C. R. C.; BEHRENS, M. A. Paradigmas educacionais e sua influência na prática pedagógica. Disponível em: http://educere.bruc.com. br/arquivo/pdf2008/541_365.pdf. Acesso em: 11 fev 2018.

GARCIA, O. M. Comunicação em prosa moderna. Rio de Janeiro: Fundação Getúlio Vargas, 1986. 
KUHN, T. A estrutura das revoluçôes cientificas. São Paulo: Perspectiva, 1991.

LE GOFF, J. Documento/monumento. In: Enciclopédia Einaudi v.1. memória-história. Lisboa: Imprensa Nacional - Casa da Moeda, 1997. p. $95-106$.

PERINI, M. A. Para uma nova gramática do português. São Paulo: Ática, 1985.

ROCHA, P. J.; MONTARDO, S. P. Netnografia: incursóes metodológicas na cibercultura. Disponível em: http://www.compos.org.br/seer/index.php/ecompos/article/download/55/55. Acesso em: 15 ago 2018.

RODRIGUES, V. V. Correlação. In: VIEIRA, S. R.; BRANDÃO, S. F. (org.). Ensino de gramática: descrição e uso. São Paulo: Contexto, 2016.

REINALDO, M. A. G. de M. O conceito de análise linguística como eixo de ensino de Lingua Portuguesa no Brasil. Disponível em: http://studylibpt. com/doc/2988843/o-conceito-de-an\%C3\%A1lise-lingu\%C3\%ADsticacomo-eixo. Acesso em: 14 abril 2018.

RIBEIRO, W. C.; LOBATO, W.; LIBERATO, R. C. Paradigma tradicional e paradigma emergente: algumas implicaçôes na educação. Belo Horizonte: Revista Ensaio, 2010. Disponível em: http:/www.scielo.br/pdf/epec/ v12n1/1983-2117-epec-12-01-00027.pdf. Acesso em: 27 nov. 2018.

SPERANÇA-CRISCUOLO, A. C. É possível ensinar sintaxe a partir do texto? O estudo do período composto. In: ABREU, A. S.; SPERANÇACRISCUOLO, A. C. (org.). Ensino de português e linguistica: teoria e prática. São Paulo: Contexto, 2016. p. 73-95.

Recebido em: 23 ago. 2019.

Aceito em: 06 dez. 2019. 